\title{
LABORATÓRIO ON-LINE DE APRENDIZAGEM: UMA EXPERIÊNCIA DE APRENDIZAGEM COLABORATIVA POR MEIO DO AMBIENTE VIRTUAL DE APRENDIZAGEM EUREK@KIDS
}

\author{
Patrícia Lupion Torres
}

\begin{abstract}
RESUMO: O estudo apresenta o ambiente virtual de aprendizagem denominadoEurek@Kids, que permite a crianças e adolescentes hospitalizados darem continuidade a sua escolarização. Tal ambiente virtual de aprendizagem resulta de um trabalho de pesquisa de professores e alunos do Programa de Pós-Graduação em Educação da PUCPR. Este projeto, financiado pelo CNPq, teve o seu início autorizado em junho de 2005, com previsão de encerramento da primeira fase em 2007. A iniciativa é alicerçada na experiência de desenvolvimento e uso do ambiente virtual de aprendizagem da PUCPR Eureka, que permite o desenvolvimento de propostas de aprendizagem colaborativas. Este trabalho apresenta ainda uma proposta metodológica de aprendizagem colaborativa, denominada Laboratório On-Line de Aprendizagem.

Palavras-chave: Aprendizagem colaborativa. Ambiente virtual de aprendizagem. Inclusão. Pedagogia hospitalar.
\end{abstract}

ONLINE LEARNING LABORATORY: A COLLABORATIVE LEARNING EXPERIMENT WITH THE USE OF THE EUREK@KIDS VIRTUAL LEARNING ENVIRONMENT

ABSTRACT: This paper presents the virtual learning environment known asEurek@Kids, which allows children and adolescents in hospital to continue their studies. The Eurek@Kids virtual learning environment is the result of research by teachers and students at the Postgraduate Education Program at PUCPR. This project, which was financially supported by CNPq, received approval to be started in

Doutora em Engenharia de Produção: Mídia e Conhecimentos e professora titular do Departamento de Educação e do Programa de Mestrado em Educação da Pontifícia Universidade Católica do Paraná (PUCPR).E-mail: patorres@terra.com.br 
June 2005, with its first phase expected to be finished in 2007. The initiative has been built upon experience gained with the development and use of the PUCPR Eureka virtual learning environment, which allows collaborative learning approaches to be developed. This paper also describes a collaborative learning approach known as On-line Learning Laboratory.

Key words: Collaborative learning. Virtual learning environment. Inclusion. Hospital pedagogy.

\section{Considerações iniciais}

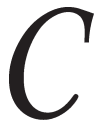

rianças e adolescentes internados em hospitais vivem experiências de primeira ou repetidas hospitalizaçōes, em um ambiente desconhecido no qual passam a conviver com a ansiedade, a dor, o sofrimento, a doença e, muitas vezes, com a incerteza da cura. $\mathrm{O}$ tempo prolongado de hospitalização é, em alguns casos, um agravante da situação de afastamento de sua família, de sua casa, de suas coisas, de seus brinquedos, de sua escola, de seus afazeres, de suas atividades de lazer, de seus amigos, enfim, de tudo que lhe é caro e que permeia seu mundo infantil.

A possibilidade de integração e interação da criança hospitalizada com colegas, professores, familiares e outros profissionais envolvidos em seu atendimento e acompanhamento pode modificar a experiência de hospitalização, amenizando os efeitos negativos que o ambiente hospitalar muitas vezes provoca nos jovens pacientes. Desenvolver atividades escolares, envolver-se no cotidiano escolar, integrar-se em equipes de trabalhos da escola, interagir com colegas e professores, participar de brincadeiras, tudo isso pode ser um fator positivo para a recuperação de crianças e jovens internados em instituição hospitalar. Mas como promover a tão necessária interação para essas crianças e adolescentes, privados do convívio social pelo processo de hospitalização?

Responder a essa questão é um dos desafios postos a educadores na atualidade. A inserção em ambientes virtuais de aprendizagem (AVA) pode ser uma das possibilidades de resposta, já que tal ferramenta permite a promoção da interação entre os diversos atores envolvidos no processo de escolarização de crianças e adolescentes hospitalizados. Vale destacar ainda que essa nova demanda de escolarização exige também novos modelos educacionais, capazes de atender às necessidades deles. 
Assim, na busca por inovações pedagógicas para propostas de escolarização hospitalar, a universidade apresenta-se como uma das responsáveis por pesquisas que respondam às exigências desse momento educacional. É nela que se encontra a resposta para atender à questão apresentada, em face da premência em se desenvolver um ambiente virtual de aprendizagem e uma proposta metodológica inovadora para a educação de crianças hospitalizadas.

Tal é a motivação deste trabalho, que apresenta o ambiente virtual de aprendizagem Eurek@Kids e uma proposta metodológica de aprendizagem colaborativa para crianças hospitalizadas.

\section{Eurek@Kids: ambiente virtual de aprendizagem}

Refletir sobre uma pedagogia hospitalar leva a encarar o significado social das diversas possibilidades operacionais das novas tecnologias educacionais, bem como do alcance estratégico da virtualidade da comunicação. E que lugar mais apropriado que a universidade para a pesquisa e o desenvolvimento de ferramentas e metodologias, tão comprometida que deve estar essa instituição com o mundo ao seu redor? A universidade se atribui a missão de criar, de inovar, de propor soluções, de desenvolver protótipos, de antecipar o futuro, de prever e de lidar com incertezas macroscópicas, já que é o espaço para construção do conhecimento.

Assim, uma das missões da universidade é a de promover o desenvolvimento social. Para Torres (2003, p. 12), "já não se trata, apenas, de formar intelectuais altamente qualificados ou de construir o repositório último do saber, da memória coletiva. É fundamental que a Universidade responda às aspirações sociais de um número cada vez maior de indivíduos". Moran (1998, p. 185) afirma que:

O nosso foco não pode permanecer só individual, mas deve estar também direcionado ao comunitário, aos grupos importantes dos quais participamos. Quanto mais pudermos inserir-nos em espaços de ação comunitária, mais cresceremos, aprenderemos, viveremos. Dentro desta perspectiva de integração pessoal e comunitária, encontraremos nas tecnologias parceiras permanentes e criativas para expandir nossas inúmeras possibilidades de informação, de comunicação e de ação.

Isto posto e diante da dificuldade de se fornecer um processo educacional de qualidade a crianças e jovens internados em hospitais, 
Laboratório on-line de aprendizagem: uma experiência de aprendizagem colaborativa...

é de fundamental importância que a universidade transforme rapidamente os novos conhecimentos que a ciência e a tecnologia produzem em soluções para a escolarização daqueles pacientes. Ainda há muito a ser feito, a fim de desenvolver ferramentas e propostas pedagógicas que respondam às necessidades desse novo modelo para a escolarização em hospital, baseado na construção coletiva do saber.

Atendendo, pois, a uma demanda social, nasce, na Pontifícia Universidade Católica do Paraná (PUCPR), o Eurek@Kids, ambiente virtual de aprendizagem, como fruto de um trabalho de pesquisa de professores e alunos do Programa de Pós-Graduação em Educação que a referida instituição oferece à comunidade em geral.

Tal projeto, financiado pelo CNPq, teve o seu início autorizado em junho de 2005, com previsão de encerramento da primeira fase em 2007. A iniciativa é alicerçada na experiência de desenvolvimento e uso do ambiente virtual de aprendizagem Eureka da PUCPR. Para Matos e Muggiatti (2006, p. 146):

O ProjetoEurek@Kids apresenta-se como uma proposta que contribui para ampliar significativamente os trabalhos que vêm sendo desenvolvidos nos hospitais, incorporando o uso das Tecnologias de Comunicação e Informação, como ferramenta de base para dar suporte às atividades para o atendimento da criança/jovem doente, diminuindo sensivelmente grandes percalços sociais, destacando-se a inclusão social, a democratização tecnológica, a promoção humana, as novas formas de comunicação e a educação inclusiva.

O processo ensino-aprendizagem no Eurek@Kids é baseado em uma mídia de terceira geração, que possibilita a interatividade, a flexibilidade e a integração entre os diversos atores do processo, garantidas pela sincronicidade e assincronicidade da comunicação. $\mathrm{O}$ ambiente virtual de aprendizagem permite uma proximidade virtual que garante a inclusão da criança em sua turma regular, apesar de seu afastamento físico. É pela interação entre os diversos atores que se supera a sensação de isolamento muitas vezes vivenciada pelas crianças e jovens hospitalizados.

Harasim (1989) realça os atributos de interação para caracterizar a educação on line como um domínio com perspectivas inteiramente novas, baseado no aprendizado colaborativo que emerge de um diálogo ativo e da exposição de idéias dos participantes do grupo. Para 
Henri (2002), a interatividade é uma das características mais importantes da comunicação e é um dos fatores determinantes da aprendizagem, pois modifica sua natureza e sua qualidade.

O ambiente virtual Eurek@Kids permite a interação e a exploração de diversas possibilidades de aprendizagem decorrentes de formas diferenciadas de comunicação: a de um para um, a de um para muitos e a de muitos para muitos.

É também por meio da interação e da comunicação que se torna possível a superação de uma das grandes dificuldades do processo de escolarização em hospitais, a da manutenção da motivação do estudante. Com a Internet é possível superar a sensação de isolamento vivenciada, pois os alunos internados mantêm uma interação constante com seus colegas de escola. Por meio da comunicação entre os diversos membros de uma "turma virtual", o aluno passa a vivenciar um sentimento de pertença.

Para Visca (1987), a pertença consiste na sensação de sentir-se parte e somente acontece em função da comunicação. Ou seja, o grau de pertença (negativo ou positivo) pode ser estimado em função da comunicação, da colaboração e da aprendizagem.

Aprendizagem colaborativa

A aprendizagem colaborativa pode ser definida como uma metodologia de aprendizagem, na qual, por meio do trabalho em grupo e pela troca entre os pares, as pessoas envolvidas no processo aprendem juntas.

Cord (2000) interpreta o trabalho de equipe como a concretização do trabalho colaborativo. Estabelece uma subordinação da colaboração à cooperação ao observar que o trabalho colaborativo depende da cooperação entre os membros de uma equipe. Elege a Internet como a ferramenta adequada para essa proposta e determina a necessidade de um produto final. Para a autora, ainda, a aprendizagem colaborativa seria um modelo de aplicação pedagógico de Internet que visa favorecer a colaboração entre pares e permite a troca de mensagens eletrônicas entre os estudantes de um grupo ou de uma turma. Dessa forma, a Internet constitui uma ferramenta para aprendizagem colaborativa. Todavia, a virtualidade instrumental desta ferramenta se empobrece quando a autora esclarece o seu 
Laboratório on-line de aprendizagem: uma experiência de aprendizagem colaborativa...

entendimento, restringindo-o à troca de mensagens eletrônicas como possibilidade de comunicação entre os membros do grupo ou da turma.

A colaboração designa atividades de grupo que pretendem um objetivo em comum, implicando a regularidade da troca, o trabalho em conjunto, a constância da coordenação. Deriva de dois postulados principais: de um lado, da rejeição ao autoritarismo à condução pedagógica com motivação hierárquica, unilateral; de outro, trata-se de concretizar uma socialização não só pela aprendizagem, mas principalmente na aprendizagem. Pode-se generalizar a idéia de que qualquer atividade desenvolvida em conjunto, animada por um objetivo final que leve a aquisições determinadas, é uma situação de aprendizagem colaborativa.

As mudanças mais significativas de uma aula tradicional para uma experiência de aprendizagem colaborativa centram-se nos papéis assumidos por alunos e professores. Modificam-se as estruturas hierárquicas e as relações de poder.

Em livro publicado pela Comissão Européia - Blueprint for interactive classroom - sobre a sala de aula interativa, tem-se apresentado o seguinte quadro comparativo, que mostra as características do processo tradicional de ensino e de aprendizagem colaborativa.

\begin{tabular}{|c|c|}
\hline $\begin{array}{l}\text { CARACTERÍSTICAS DO PROCESSO DIDÁTICO } \\
\text { DO ENSINO TRADICIONAL }\end{array}$ & $\begin{array}{l}\text { CARACTERÍSTICAS DA APRENDIZAGEM } \\
\text { COLABORATIVA }\end{array}$ \\
\hline $\begin{array}{c}\text { O professor é o responsável pela } \\
\text { aprendizagem. }\end{array}$ & O aluno é responsável pela aprendizagem. \\
\hline O ensino é um processo de instrução. & $\begin{array}{l}\text { O ensino-aprendizagem é um processo de } \\
\text { construção. }\end{array}$ \\
\hline Os alunos são passivos. & Os alunos são ativos. \\
\hline O professor instrui e dá aulas expositivas. & $\begin{array}{l}\text { O professor facilita e aconselha (o professor atua } \\
\text { como um tutor) }\end{array}$ \\
\hline $\begin{array}{l}\text { O aluno trabalha com material apenas escrito, } \\
\text { gravado ou televisionado. }\end{array}$ & $\begin{array}{l}\text { O aluno tem possibilidade de ter acesso a um } \\
\text { número muito grande de informações por meio } \\
\text { das novas tecnologias educacionais. }\end{array}$ \\
\hline O aluno recebe informação. & $\begin{array}{l}\text { O aluno é uma pessoa criativa que resolve } \\
\text { problemas e usa a informação. }\end{array}$ \\
\hline Projetos e conquistas individuais. & Trabalho colaborativo. \\
\hline
\end{tabular}

Fonte: http://www.avd.kuleuven.ac.be/bic/products/handbook/handbookchapters/01hdbkindex.html 
Resumidamente, pode-se afirmar que na metodologia colaborativa: a aprendizagem é um processo ativo que se dá pela construção colaborativa entre os pares; os papéis do grupo são definidos pelo próprio grupo; a autoridade é compartilhada; o professor é um facilitador, um parceiro da comunidade de aprendizagem; ocorre a centralização da responsabilidade da aprendizagem no aluno, existe a co-responsabilidade pelo processo de aprendizagem do colega.

Matthews et al. (2006) destacam as principais características da aprendizagem colaborativa:

- Cabe aos próprios alunos a organização do grupo;

- a definição de papéis é negociada e definida pelos alunos;

- o professor encaminha as perguntas de volta para os próprios alunos responderem;

- o trabalho avaliado pelos alunos em sala não é entregue ao professor, sendo apenas mais um estágio do trabalho final;

- os alunos não recebem treinamento especial para trabalharem em grupo, pois o professor acredita que eles são participantes responsáveis que já usam habilidades sociais para desenvolver e completar atividades no trabalho colaborativo;

- os alunos resolvem os conflitos no grupo;

- os teóricos e praticantes dessa proposta metodológica tendem a vir da área humanística e das ciências sociais.

Um estudo feito por Laister e Kober (2005) aponta alguns motivos para a aprendizagem colaborativa (AC) apresentar-se como uma forma de ensino bem-sucedida. Destacam-se:

- A eficácia da aprendizagem tanto em curto prazo, com relação ao aprendizado do assunto proposto, quanto da aprendizagem em longo prazo;

- a eficácia do desenvolvimento das habilidades cognitivas e de auto-estima;

- comparada a situaçóes de aprendizagem individual ou de simples trabalho de grupo, a aprendizagem colaborativa promove um nível mais elevado de desempenho dos alunos, aumenta sua habilidade de resolução de problemas e auxilia no desenvolvimento de traços positivos de personalidade; 
Laboratório on-line de aprendizagem: uma experiência de aprendizagem colaborativa...

- a aprendizagem colaborativa habilita o sujeito para viver de forma mais autônoma e mais colaborativa.

Tem-se, pois, na aprendizagem colaborativa, a atenção centrada não somente no momento presente do aluno e na aprendizagem dos conteúdos ministrados, mas também no seu futuro como cidadão, com o desenvolvimento de habilidades pessoais que podem trazer benefícios sociais e profissionais.

Apresentando uma proposta metodológica para o processo de escolarização de crianças hospitalizadas

Em face de tantas pressões decorrentes do ambiente hospitalar, ante os anseios de familiares e pacientes, atendendo ao maior espectro possível de demandas de escolarização em ambiente hospitalar, as soluções institucionais e metodológicas precisam ser reinventadas. As conjunturas são inéditas, os recursos também, o que torna inaceitável desperdiçar oportunidades de flexibilizar, de avançar, de enriquecer, de socializar as situações formativas.

Embora sejam muitas as instituições que desenvolvem programas educacionais por meio de ambientes virtuais de aprendizagem, bem como utilizam recursos tecnológicos para "entregar" a informação ao discente, poucas inovam na criação de abordagens educacionais que promovam a produção de conhecimento e menos ainda inovam, trabalhando com tal ferramenta em ambiente hospitalar.

Tem-se, então, como um dos principais desafios da pedagogia hospitalar, o desenvolvimento de um modelo criativo, inovador, que responda à necessidade de escolarização de crianças e adolescentes hospitalizados. Presencia-se um momento educacional que exige o desenvolvimento de um modelo pedagógico para o trabalho com crianças e adolescentes hospitalizados. Há muito a experimentar, a inovar, a criar, já que se está diante de uma tecnologia (Internet) que permite recursos até então impensáveis. Vale ressaltar as idéias de Moran (1998, p. 86):

A Internet ajuda a desenvolver a intuição, a flexibilidade mental, a adaptação a ritmos diferentes. A intuição, porque as informações são descobertas por acerto e erro, por conexôes "escondidas". As conexôes não são lineares, vão "linkando-se" por hipertextos, textos interconectados, mas ocultos, com 
inúmeras possibilidades diferentes de navegação. Desenvolve a flexibilidade porque a maior parte das seqüências são imprevisíveis, abertas. A mesma pessoa costuma ter dificuldades em refazer a mesma navegação duas vezes, também ajuda na adaptação, a ritmos diferentes: a Internet permite a pesquisa individual, em que cada um siga seu próprio ritmo, e a pesquisa em grupo, em que se desenvolve o aprendizado colaborativo.

Obraztsov (1984), referindo-se a outro contexto, afirma que os métodos, até então em uso, devem ser substituídos por outros e por meios que possam tornar mais intensivo o processo educativo, inclusive para permitir, tanto aos professores como aos estudantes, economizar tempo e esforços. Nessa perspectiva, o processo educativo em ambiente escolar poderia ser aperfeiçoado graças a um ambiente pedagógico qualitativamente novo, combinado a equipamentos, programas, métodos e meios tecnológicos renovados.

Dessa forma, tem-se no uso de ambientes virtuais de aprendizagem, por meio de uma intervenção colaborativa, uma possibilidade de inovação para a pedagogia hospitalar. Neste trabalho os alunos poderiam buscar novas oportunidades, mais adequadas às suas necessidades. Porém, apenas a tecnologia, em constante evolução, não garante a evolução pedagógica necessária a esse processo de escolarização para crianças hospitalizadas.

Observa-se que muitas das propostas existentes enquadram-se, em termos de modelos pedagógicos, em concepções tradicionais de ensino, na reprodução do conhecimento: é a educação bancária, descrita por Freire $(1975,1999)$. Nesta perspectiva, a idéia central é a do repasse da informação: o professor ensina quando "transmite" a informação e o aluno aprende quando assimila e memoriza o que lhe for repassado.

O trabalho aqui apresentada do Laboratório On-Line de Aprendizagem (LOLA), por meio do ambiente virtual Eurek@Kids, fundamenta-se na interação e no diálogo. Aprender significa construir coletivamente o conhecimento, a partir de uma atitude crítica, problematizadora e questionadora, e ensinar significa animar, orientar, propor, a fim de fomentar a discussão entre pares.

LOLA - uma metodologia de aprendizagem colaborativa para o ambiente virtual de aprendizagem Eurek@Kids

O Laboratório On-Line de Aprendizagem (LOLA) é uma proposta metodológica de aprendizagem colaborativa que coloca em prática 
Laboratório on-line de aprendizagem: uma experiência de aprendizagem colaborativa...

tais pressupostos teóricos por meio do desenvolvimento de atividades programadas. Tais atividades, individuais ou grupais, são propostas para promover a construção do conhecimento por meio da pesquisa. Têm por objetivo formar sujeitos pesquisadores nos mais diversos níveis educacionais.

São as atividades do LOLA que organizam, sistematizam, dinamizam e, conseqüentemente, dão sentido à ação do grupo. E é por meio da gestão das atividades que seus membros exercitam a democracia do consenso.

Toda proposta de trabalho é elaborada, definida e negociada colaborativamente e esta é uma forma de promover a integração do aluno hospitalizado com seus colegas de turma. Assim, são os próprios componentes do grupo que, com o auxílio de um processo de mediação do professor, se organizam, repartem tarefas, assumem papéis, discutem propostas, idéias, posiçóes, fazem proposições, enfim, interagem entre si.

\section{As atividades do LOLA}

O Laboratório é implementado por meio do desenvolvimento de suas oito atividades fundamentais, como segue:

1 - Comentar textos selecionados pelo professor e disponibilizados no ambiente virtual de aprendizagem. Nessa atividade, o professor apresenta aos alunos textos relativos aos conteúdos a serem por eles trabalhados. Corresponde, na atividade de pesquisa, ao que se chama de leitura de bases teóricas. Tais textos são disponibilizados pelo professor na ferramenta Roteiros.

O aluno, individualmente ou em grupo, deve, após a leitura, publicar comentário no AVA sobre o texto lido, que pode ainda receber novos comentários de outro aluno ou equipe.

2 - Produzir mapa conceitual sobre o texto lido. Essa atividade implica elaborar um mapa conceitual, sintetizando as idéias principais do texto. Ela pode ser realizada em um editor de texto, ou em site especializado como <http://cmap.ihmc.us $>$.

A técnica de mapas conceituais se fundamenta na Teoria da Aprendizagem Significativa de Ausubel e, posteriormente, nas pesquisas de John Novak. Ela pode ser usada na maioria das situaçóes do cotidiano que envolve ensino, aprendizagem ou pensamento. Ajuda a fazer planejamentos, anotações e listas, a elaborar projetos, a preparar apresentaçóes, 
a analisar e resolver problemas; a memorizar conteúdos e informações, a elaborar relatórios, artigos e apresentações.

\section{Figura 1}

(Tela doEurek@Kids - Roteiros)

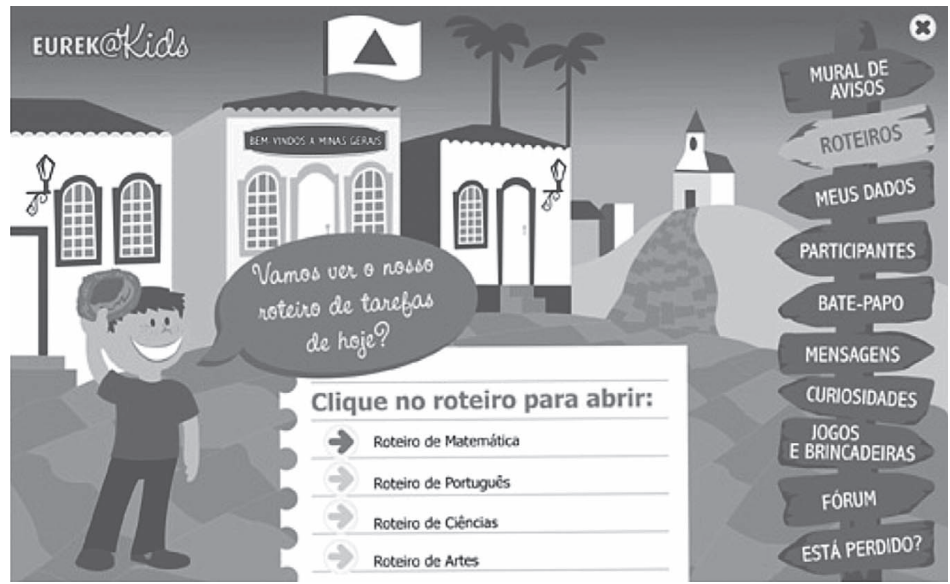

Fonte: Tela elaborada por Josiane Maria Bortolozzi.

3 - Inserir links, propondo novas conexões entre os conhecimentos sistematizados. Nessa atividade cabe ao aluno selecionar na Internet textos sobre o conteúdo em pauta e disponibilizá-los para seus colegas com seus comentários na ferramenta Curiosidades.

Veja que os textos são propostos por alunos, para alunos, tornando-os co-responsáveis pelo processo ensino-aprendizagem de seus pares. Após a leitura do texto proposto pelo colega, o aluno, individualmente ou em grupo, deve publicar comentários sobre o texto lido. A cada nova leitura feita por um outro elemento da turma o texto pode receber novos comentários.

4 - Rever o mapa conceitual elaborado. Nessa atividade, após a leitura dos textos disponibilizados pelos colegas, o aluno deve rever e completar seu mapa conceitual elaborado anteriormente e publicá-lo com as correções no AVA. 


\section{Figura 2}

(Tela doEurek@Kids - Curiosidades)

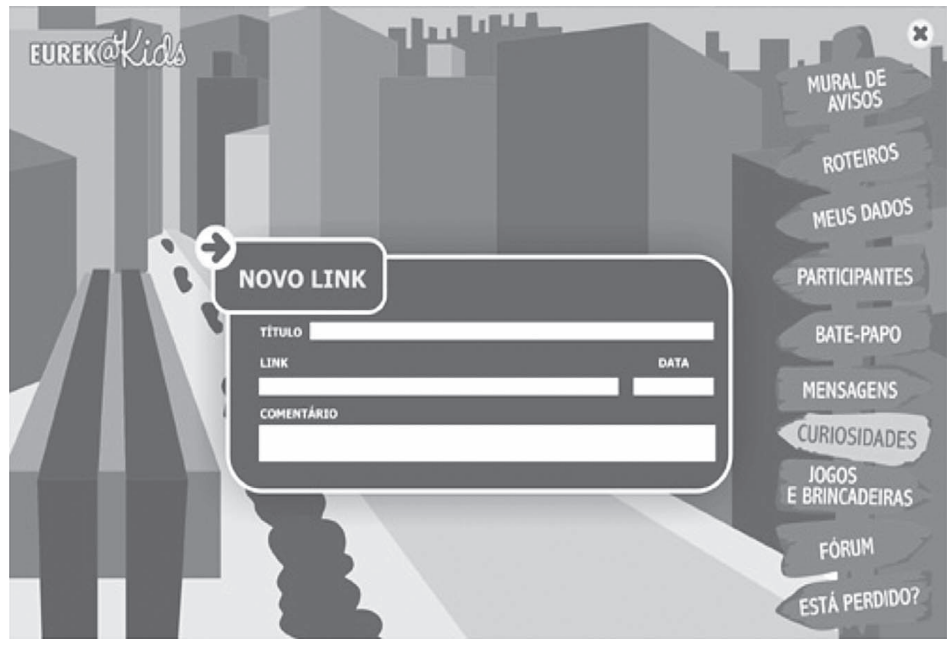

Fonte: Tela elaborada por Josiane Maria Bortolozzi.

5 - Questionar o conhecimento existente. Essa atividade consiste em elaborar questóes sobre o conteúdo proposto para serem trabalhadas. No LOLA, as perguntas são elaboradas por alunos e para alunos, exercitandose assim, já neste momento, uma atitude reflexiva nas crianças e jovens hospitalizados, que deixam de ser passivos do processo para assumiremse como partícipes do mesmo. Tal atividade deve ser desenvolvida ora individualmente, ora em grupo. As questôes elaboradas devem ser publicadas na ferramenta Fórum do AVA.

6 - Responder aos questionamentos elaborados. Por meio dessa atividade, os alunos devem selecionar questôes para responder, publicadas na ferramenta Fórum do AVA.

Nesse exercício estão claros dois pressupostos montessorianos intimamente relacionados: o da livre escolha e o da liberdade com responsabilidade (Montessori, 1965). Ou seja, o aluno tem liberdade para escolher que perguntas ele responderá, porém, deve obrigatoriamente respondê-las na quantidade mínima estabelecida. 
Figura 3

(Tela do Eurek@Kids - Fórum)

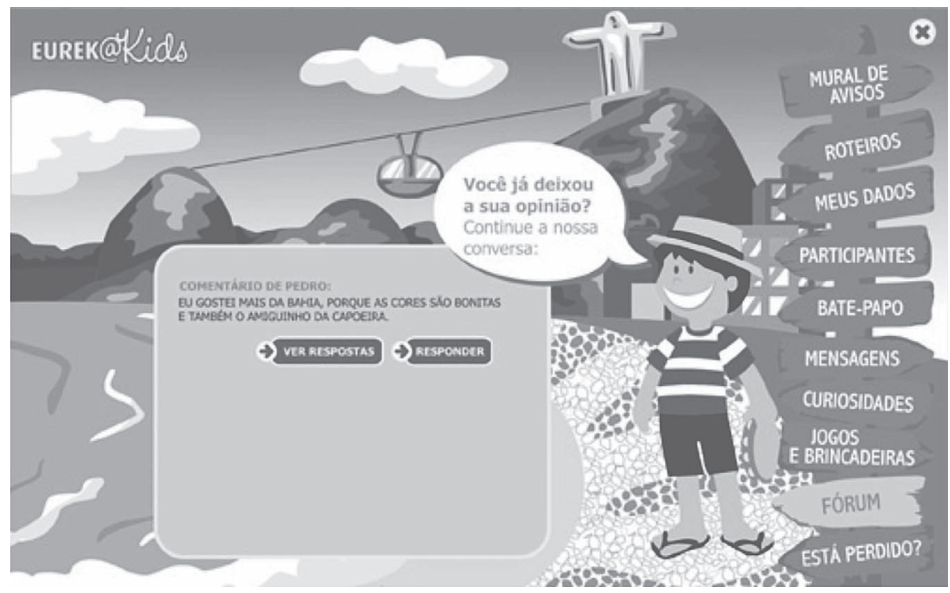

Fonte: Tela elaborada por Josiane Maria Bortolozzi.

Figura 4

(Tela doEurek@Kids - Fórum)

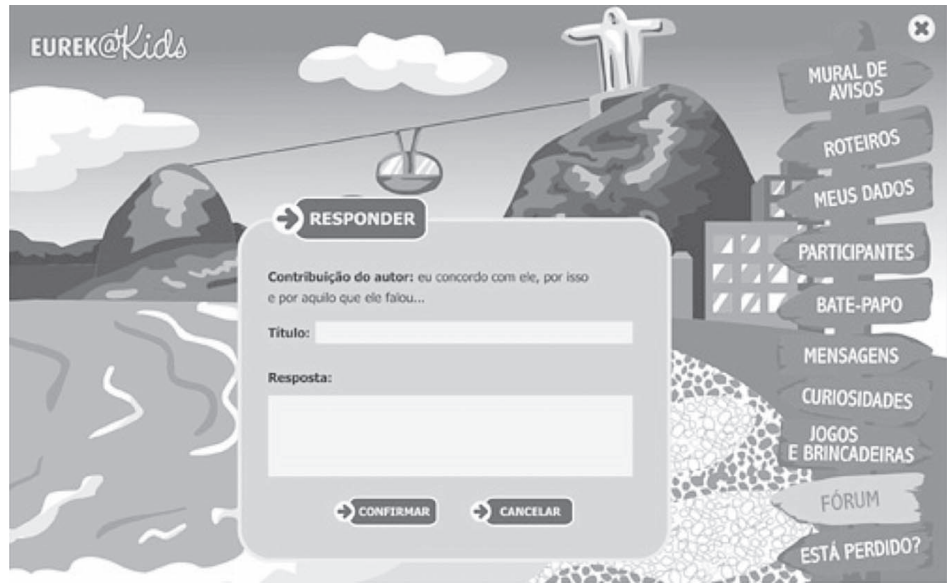

Fonte: Tela elaborada por Josiane Maria Bortolozzi. 
Laboratório on-line de aprendizagem: uma experiência de aprendizagem colaborativa...

$\mathrm{Na}$ atividade individual, eles seguem seu próprio critério tanto para a escolha das perguntas, quanto para o conteúdo, a complexidade e a extensão da resposta. Já na atividade em grupo, faz-se necessário negociar para se chegar a um consenso sobre as possibilidades de escolha, desenvolvendo, assim, habilidades de convívio social.

Ao estabelecer critérios para a seleção de perguntas, os alunos já fazem um exercício de avaliação. Cumpre-se assim um dos objetivos do Laboratório On-Line, que é exatamente o de propiciar aos alunos essas diversas reflexões e destacar a importância do processo sobre o produto. Pretende-se, dessa maneira, desenvolver nos alunos o espírito crítico, a autonomia, a responsabilidade, a iniciativa e a criatividade.

7 - Produzir novos conhecimentos. Todas as atividades anteriores preparam os alunos para a atividade de construção de texto coletivo. $\mathrm{O}$ primeiro momento da atividade consiste em escolher um título para o texto que irão produzir. No segundo momento, os alunos iniciam a produção do texto propriamente dito. Cada aluno deve iniciá-lo elaborando um parágrafo que será anexado a todos os outros produzidos

\section{Figura 5}

(Tela doEureka@Kids - Jogos e brincadeiras)

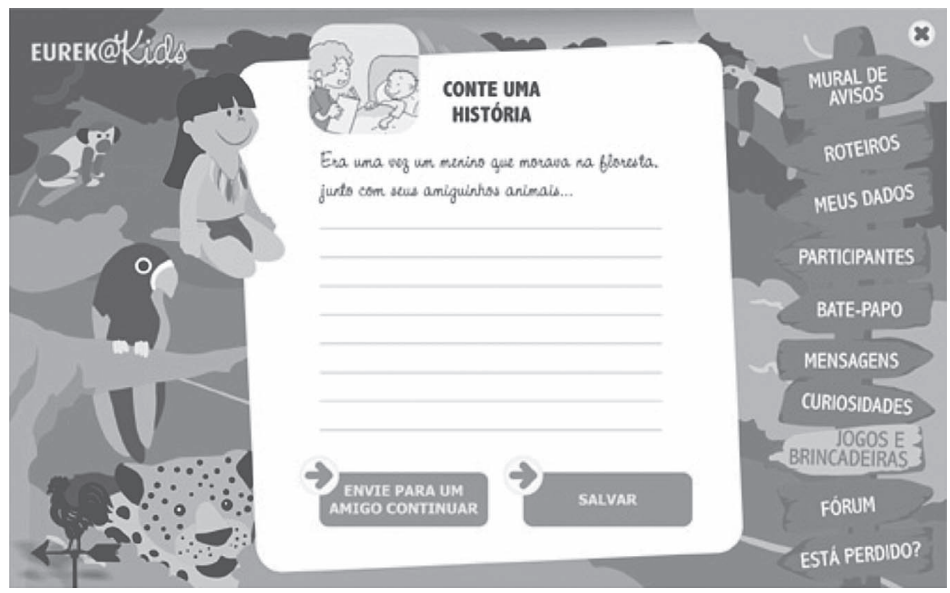

Fonte: Tela elaborada por Josiane Maria Bortolozzi. 
pelos outros colegas do grupo. Em seguida, cada elemento da equipe escreve sua contribuição, que é partilhada com todos e que, por sua vez, completam, refutam ou acrescentam idéias. Assim, todos juntos têm uma ação recíproca sobre o texto, produzindo o conhecimento.

8 - A última atividade dessa proposta de aprendizagem colaborativa é $a$ de avaliar todos os procedimentos realizados. Destaca-se que se realiza uma avaliação do processo e não dos diversos produtos conseqüentes das atividades.

Essa atividade é sempre desenvolvida em grande grupo, via chat, conforme o estabelecido no início dos trabalhos com a turma. O processo de avaliar ocorre sempre ao final do ciclo das atividades, seja individual ou grupal.

\section{Figura 6}

(Tela do Eurek@Kids - Bate-papo)

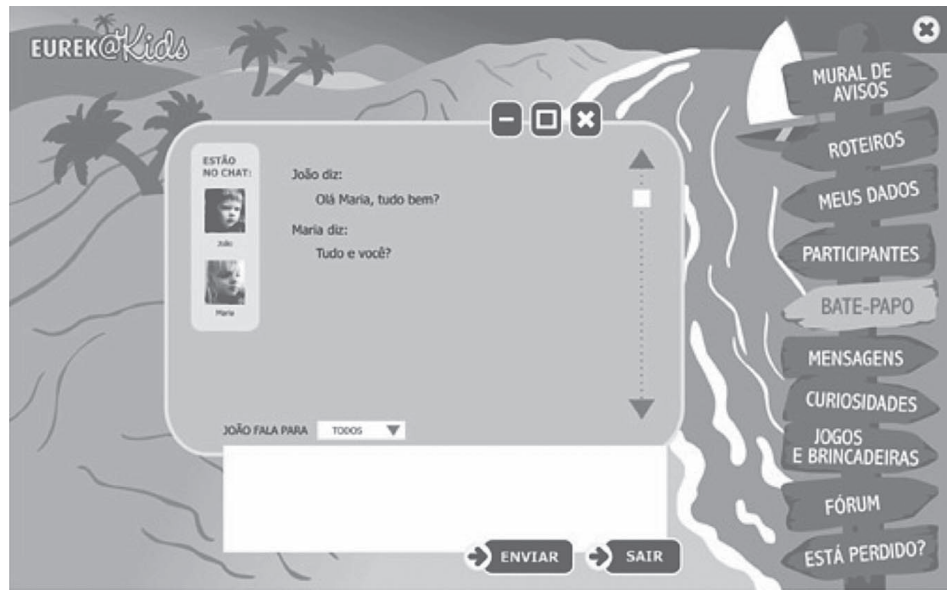

Fonte: Tela elaborada por Josiane Maria Bortolozzi

\section{Breves considerações finais}

Consideradas as premissas do presente trabalho, assim como as observações registradas a partir do desenvolvimento de um modelo alternativo 
Laboratório on-line de aprendizagem: uma experiência de aprendizagem colaborativa...

de aprendizagem colaborativa para o processo de escolarização de crianças e jovens hospitalizados, são pertinentes as seguintes consideraçôes preliminares:

- Trabalhar com pedagogia hospitalar ainda constitui um desafio metodológico. São inúmeras as soluçōes pedagógicas possíveis, principalmente quando se propóe ultrapassar o paradigma do trabalho estritamente individualizado.

- As soluçóes pedagógicas que pretendem socializar a aprendizagem - construção do saber no grupo - implicam uma maior exploração dos recursos de mediação tecnológica, disponíveis no ambiente virtual Eurek@Kids - especialmente daqueles que neutralizam o distanciamento físico e temporal passível de se fazer sentir entre aprendizes hospitalizados.

- A comunicaçăo on-line, segundo a conduta adotada no LolA, pode levar a uma integração virtual, aproximando os diversos atores do processo de ensino-aprendizagem pelo respaldo proporcionado à comunicação pedagógica. Supera, desse modo, uma das maiores dificuldades do processo de escolarização de crianças e jovens hospitalizados, que é a separação física entre professor e aluno internado, e, no caso da aprendizagem colaborativa, a separação física entre os pares discentes.

- É possível desenvolver, simultânea e concorrentemente, uma condição de autonomia no processo de aprendizagem colaborativa no ambiente virtual de aprendizagem Eurek@Kids. No LOLA, em uma primeira instância, reconhece-se a autonomia do discente, ao realizar atividades individuais; em uma segunda instância, o próprio grupo constrói um saber autonomamente, já que o professor não interfere nas decisões do grupo de modo restritivo.

Recebido em abril de 2007 e aprovado em outubro de 2007.

\section{Referências bibliográficas}

CORD, B. Internet et pédagogie: état des lieux. Disponível em: $<$ http://wwwadm.admp6.jussieu.fr/fp/uaginternetetp/definition travail_collaboratif.htm>. Acesso em: 4 jul. 2000. 
FREIRE, P. Pedagogia do oprimido. Rio de Janeiro: Paz \& Terra, 1975.

FREIRE, P. Pedagogia da autonomia: saberes necessários à prática educativa. Rio de Janeiro: Paz \& Terra, 1999.

HARASIM, L. On-line education: a new domain. In: MASON, R; KaYe, A. (Ed.). Mindweave: communication, computers and distance instruction. Oxford: Pergamon, 1989.

HENRI, F. Formation à distance et téléconférence assistée par ordinateur: interativité, quasi-interativité, ou monologue? Journal of Distance Education/Revue de l' Enseignement à Distance, Ottawa, v. 7, n. 1, 1992. Disponível em: <http://cade.athabascau.ca/vol7.1/07_henri_9html?>. Acesso em: 28 mar. 2002.

INSTITUTE FOR HUMAN MACHINE COGNITION (IHMC). CMAP Tools. Pensacola: West Florida University. Disponível em: <http://cmap.ihmc.us/>. Acesso em: 26 out. 2003.

LAISTER, J.; KOBER, S. Social aspects of collaborative learning in virtual learning environments. 2005. Disponível em: <http://comma.doc.ic.ac.uk/ inverse/papers/patras/19.htm>. Acesso em: 7 jan. 2006.

MATOS, E.L.M.; MUGGIATTI, M. Pedagogia hospitalar: a humanização integrando educação e saúde. Petrópolis: Vozes, 2006.

MATTHEWS, R.S. et al. Building bridges between cooperative and collaborative learning. Cooperative Learning and College Teaching Newsletter, v. 6, n. 1, p. 2-5. Disponível em: <http://www.csudh.edu/ SOE/cl_network/RTinCl.html\#building>. Acesso em: 6 jan. 2006

MONTESSORI, M. Pedagogia científica: a descoberta da criança. São Paulo: Flamboyant, 1965.

MORAN, J. M. Mudanças na comunicação social. São Paulo: Paulinas, 1998.

OBRAZTSOV, I. Science, technologie et enseignement superieur. In: UnESCO. Réflexion sur le developpment futur de l'éducation. Paris, 1984. p. 157-160. 
Laboratório on-line de aprendizagem: uma experiência de aprendizagem colaborativa...

TORRES, P.L. O Laboratório on-line de aprendizagem: uma proposta crítica de aprendizagem colaborativa para a educação. Florianópolis: UNISUL, 2003.

VISCA, J. Clinica psicopedagógica: epistemologia convergente. Porto Alegre: Artes médicas, 1987. 